Arq. Bras. Med. Vet. Zootec., v.66, n.1, p.253-258, 2014

\title{
Desempenho de bovinos Tabapuã e seus cruzados em pastagens de braquiária no estado da Bahia
}

\author{
[Performance of straightbred and crossbred Tabapuã cattle on \\ brachiaria pasture in Bahia state] \\ F.A. Barbosa ${ }^{1}$, D.N. Borges ${ }^{2}$, S.L.S. Cabral Filho ${ }^{2}$, D.S. Graça ${ }^{1}$, V.J. Andrade ${ }^{1}$, \\ C.E. Souza ${ }^{1}$, J.M. Leão ${ }^{1}$, R.A. Mandarino ${ }^{1}$ \\ ${ }^{1}$ Escola de Veterinária - Universidade Federal de Minas Gerais - Belo Horizonte, MG \\ ${ }^{2}$ Universidade de Brasília - Faculdade de Agronomia e Medicina Veterinária - Brasília, DF
}

\begin{abstract}
RESUMO
Comparou-se o desempenho de bovinos de diferentes grupos genéticos quanto a algumas características produtivas da desmama até o abate. Os dados são referentes a 827 bovinos machos oriundos do cruzamento de vacas Tabapuã com touros Tabapuã (TAB), Red Angus (REDTAB), Santa Gertrudis (STATAB), e das fêmeas TabapuãxRed Angus com touros Santa Gertrudis (STAREDTAB) (nascidos entre 1999 e 2001 e criados em pastagens de braquiária, no Estado da Bahia). Foram analisados o peso à desmama ajustado aos 205 dias (PD205), o peso ao abate (PA), o ganho médio diário da desmama ao abate (GMD) e a idade ao abate (IA). O grupo contemporâneo (GC), o grupo genético (GG) e a interação entre GC e GG influenciaram as características avaliadas $(\mathrm{P}<0,05)$. O REDTAB apresentou superioridade entre os GG para GMD no primeiro ano do GC $(1 \mathrm{GC})$, com média de $0,552 \mathrm{~kg}(\mathrm{P}<0,05)$. Os cruzados STATAB e STAREDTAB não apresentaram diferenças significativas para as médias de GMD $(\mathrm{P}>0,05)$; entretanto, apresentaram médias inferiores às do grupo REDTAB e TAB. Em condição de ambiente mais favorável, o REDTAB pode ser mais precoce, obtendo maior GMD e PA com menor IA, sendo superior ao Tabapuã e aos cruzados da segunda geração (F2). Os cruzados F2 não demonstraram vantagem em relação ao cruzado $\mathrm{F} 1 \mathrm{e}$ à raça pura.
\end{abstract}

Palavras-chave: Tabapuã, cruzamento, ganho diário, grupo genético, peso ao abate, peso à desmama

\begin{abstract}
The aim of this study was to compare the different genetic groups performances from weaning to slaughter. The data are referred to 827 male calves of Tabapuã cows crossed with Red Angus (REDTAB) and Santa Gertrudis sires and from Tabapuã x Red Angus cows crossed with Santa Gertrudis sires, born from 1999 to 2001 and raised in Brachiaria pastures, in Bahia state, Brazil. The weaning weight was adjusted to 205 days (WW205), slaughter weight (SW), average daily gain from weaning to slaughter $(A D G)$ and age slaughter $(A G)$, were analyzed. The contemporary group $(C G)$, genetic group $(G G)$ and the interaction between $C G$ and $G G$ influenced the parameters $(P<0.05)$. The REDTAB showed superiority between $G G$ for $A D G$ in $1 C G$, with an average of $0.522 \mathrm{~kg}(P<0.05)$. The crossbreed STATAB and STAREDTAB weren't different to ADG (P>0.05), however, had lower averages than REDTAB and $T A B$. In more favorable environmental conditions, REDTAB should get higher ADG and SW and lower $A G$, being superior than Tabapuã and to the second generation's crossbred (F2). The crossbred F2 showed no advantage over Flcrossbred and straightbred.
\end{abstract}

Keywords: Tabapuã, crossbreeding, average gain, genetic group, slaughter age, weaning age

Recebido em 30 de agosto de 2012

Aceito em 6 de agosto de 2013

E-mail: fabianoalvimvet@hotmail.com 


\section{INTRODUÇÃO}

As raças zebuínas (Bos indicus), em geral, apresentam crescimento mais lento e produzem carcaça mais leve, carne com qualidade inferior e maior variabilidade que as raças europeias (Bos taurus), que são altamente produtivas e mais exigentes no manejo (Cruz et al., 2004; Menezes et al., 2005). Entretanto, o zebu apresenta maior rusticidade, suporta bem as condições climáticas do país tropical, e é bem resistente a endo e ectoparasitas. $\mathrm{O}$ animal resultante do cruzamento entre raças zebuínas e europeias incorpora vantagens, como maior precocidade, resistência aos parasitas, adaptabilidade e alto potencial de crescimento, como foi avaliado por Euclides Filho et al. (2004).

Segundo Rosa (1999), da população de bovinos, estimada em 170 milhões de cabeças, apenas 0,2\% são constituídos pelas raças sintéticas Bos taurus $x$ Bos indicus. O cruzamento entre as raças europeias e zebuínas vem sendo utilizado como forma de melhorar a eficiência da produção de carne, promovendo até $100 \%$ de heterose, com incorporação de genes desejáveis de forma rápida e, ainda, a complementação de características desejáveis de duas ou mais raças (Rennó et al., 2000). A diferença genética existente entre as raças utilizadas influi diretamente na manifestação da heterose, sendo que a heterose ocasionada pelo acasalamento entre zebu e taurino é cerca de duas vezes a proporcionada por um acasalamento de taurinotaurino ou zebuíno-zebuíno (Fries, 1996).

Koch et al. (1989) verificaram que o cruzamento entre raças pode resultar em aumentos de produção de até $50 \%$ em ambientes subtropicais. Muniz e Queiroz (1999) observaram que os cruzados apresentaram maior ganho de peso em relação à raça pura Nelore, com variação de 5 a $44 \%$, dependendo do cruzamento e da idade do animal, e apresentaram maior peso à desmama e aos 550 dias de idade.

O objetivo deste trabalho foi avaliar o peso à desmama, peso ao abate, idade ao abate e ganho médio diário da desmama ao abate de animais da raça Tabapuã e seus cruzados, criados em sistema semi-intensivo de ciclo completo de bovinos de corte, em pastagens de braquiária, no Estado da Bahia.

\section{MATERIAL E MÉTODOS}

O conjunto de 827 registros analisado foi obtido de um rebanho comercial de bovinos machos de composição racial zebuína, sendo a base Tabapuã (TAB), e um composto Bos taurus x Bos indicus, representado pelos seguintes grupos genéticos: 1/2Red Angus x 1/2Tabapuã (REDTAB), $1 / 2$ Santa Gertrudis X $1 / 4$ Red Angus $1 / 4$ Tabapuã (STAREDTAB), 1/2Santa Gertrudis x 1/2Tabapuã (STATAB), nascidos entre setembro de 1999 e fevereiro de 2001.

A propriedade estava localizada no município de Lajedão, Bahia, de clima Tropical Brasil Central. O sistema de produção era de ciclo completo, com bovinos criados em pastagens de Brachiaria brizantha cv. Marandu, Brachiaria decumbens cv. Basilisk e Brachiaria humidicula durante todo o ano, com a taxa de lotação média de 1,24 cabeças por hectare (ha). As áreas de rotação eram compostas por seis módulos, sendo um de 114 e cinco de 80 hectares, totalizando 514 ha.

Os bovinos receberam suplemento mineral durante a época das águas com formulação específica para cada categoria. Os bezerros em amamentação foram suplementados em sistema de creep-feeding. Na época da seca, as categorias de recria e engorda receberam suplemento proteico-mineral com ingestão média diária de $0,1 \%$ e $0,2 \%$ do peso vivo, respectivamente. Todos os animais foram pesados à desmama e ao abate e/ou venda. $\mathrm{O}$ peso a desmama foi ajustado para 205 dias, usando a fórmula: PD205 $=((P D-$ PN/ID) x 205 dias)+PN; em que PN é o peso ao nascimento, PD é o peso à desmama e ID é a idade à desmama. $\mathrm{O}$ ganho médio diário (GMD) da desmama ao abate foi obtido pela razão da diferença entre o peso observado ao abate e o peso observado aos 205 dias, pelo número de dias contidos no período compreendido entre as duas pesagens.

O período da estação de monta foi de 120 dias, em média, começando em novembro e terminando em março, com algumas variações em função da ocorrência de seca prolongada ou veranicos que poderiam afetar a qualidade e a disponibilidade da forrageira. As matrizes zebuínas foram inseminadas com sêmen de touro Red Angus e Santa Gertrudis. As fêmeas do cruzamento Tabapuã x Red Angus (F1) foram inseminadas com Santa Gertrudis, dando origem 
a um composto de três raças. Outras matrizes zebuínas foram inseminadas com Tabapuã para preservar a base genética zebuína. Foram definidos dois grupos contemporâneos (GC), sendo $1 \mathrm{GC}$, contendo dados de animais nascidos nos meses de setembro de 1999 a fevereiro de 2000; 2GC, nascidos de setembro de 2000 a fevereiro de 2001 (Tab. 1).

Tabela 1. Distribuição dos animais conforme o grupo de contemporâneos (GC) e o grupo genético (GG)

\begin{tabular}{lccc}
\multicolumn{1}{c}{ Grupo genético } & $1 \mathrm{GC}$ & $2 \mathrm{GC}$ & Total \\
\hline TAB - cabeças & 103 & 144 & 247 \\
REDTAB - cabeças & 112 & 111 & 223 \\
STATAB - cabeças & 17 & 9 & 26 \\
STAREDTAB - cabeças & 132 & 199 & 331 \\
\hline Total & 364 & 463 & 827 \\
\hline
\end{tabular}

TAB: Tabapuã; REDTAB: 1/2Red Angus x 1/2Tabapuã; STATAB: 1/2Santa Gertrudis x 1/2Tabapuã; STAREDTAB: 1/2Santa Gertrudis x 1/4Red Angus x 1/4Tabapuã, sendo que a raça paterna aparece em primeiro lugar. 1GC: animais nascidos nos meses de setembro de 1999 a fevereiro de 2000; 2GC: nascidos de setembro de 2000 a fevereiro de 2001.

O modelo estatístico utilizado foi o inteiramente ao acaso, em esquema fatorial $4 \times 2: Y_{i j k}=\mu+a_{i}$ $+\mathrm{b}_{\mathrm{j}}+(\mathrm{ab})_{\mathrm{ij}}+\mathrm{E}_{\mathrm{ijk}}$, onde $\mathrm{Y}_{\mathrm{ijk}}=$ variável dependente do grupo genético $i$, no grupo contemporâneo $\mathrm{j}$ e na repetição $\mathrm{k} ; \mu=$ média geral, $\mathrm{a}_{\mathrm{i}}=$ efeito do iésimo grau do grupo genético, onde $1=\mathrm{TAB}, 2=\mathrm{REDTAB}, 3=$ STATAB e $4=$ STAREDTAB; $b_{j}=$ efeito do jésimo grau dos grupos contemporâneos 1 e 2; $\mathrm{E}_{\mathrm{ijk}}=$ erro experimental do grupo genético i no grupo contemporâneo $\mathrm{j}$, na repetição $\mathrm{k}$.

A análise de variância foi feita pelo PROC GLM do SAS (Statistical..., 1990) e as médias, comparadas pelo teste Tukey com $95 \%$ de significância. O peso ao desmame (PD) foi analisado como uma co-variável.

\section{RESULTADOS E DISCUSSÃO}

As médias para o peso à desmama (PD205), peso ao abate (PA), ganho médio diário da desmama ao abate (GMD) e idade ao abate (IA) foram de 212,80, 459,64, 0,464kg e 749 dias, respectivamente (Tab. 2). O PD205 médio dos animais da raça Tabapuã foi mais elevado que o encontrado por Sakaguti et al. (2003), de $167,71 \mathrm{~kg}$, considerando animais que foram criados em sistema de pastagem, e acima do encontrado por Vieira et al. (2005), para bezerros Nelore de $170 \mathrm{~kg}$, durante quatro anos de avaliação, 1997 a 2000. Ferraz Filho et al. (2002), utilizando o banco de dados da Associação Brasileira dos Criadores de Zebu $(\mathrm{ABCZ})$, estudaram as características de peso à desmama de animais Tabapuã corrigidos para 205 dias de idade (PD205), em regime exclusivo de pastagens, nascidos no período de 1959 a 1996, e obtiveram valores inferiores aos do presente estudo para PD205 de $170 \mathrm{~kg} \pm 24,51$. Em estudo com dados mais recentes, Ribeiro et al. (2009) verificaram valores médios aos 205 dias de $172,53 \mathrm{~kg} \pm 21,55$, para P365 de $221,94 \mathrm{~kg} \pm 29,82$ e para P550 de $281,25 \mathrm{~kg} \pm 37,86$, e relataram maior influência do efeito materno como sendo fator importante no peso à desmama para animais Tabapuã, embora tenham observado essa influência desde o peso ao nascimento.

Muniz e Queiroz (1998) encontraram peso à desmama aos 230 dias de 191,52, 183,82, e $195,17 \mathrm{~kg}$ para bezerros AngusxNelore, Brangus $x$ Nelore e Simental x Nelore, respectivamente. O valor mais elevado do PD205 dos cruzados de Tabapuã do presente estudo pode ser explicado pela suplementação alimentar (creep-feeding), o efeito do ambiente e a diferença de seleção genética entre os rebanhos das diferentes pesquisas relatadas acima, conforme mencionado por Nogueira et al. (2006), Barros et al. (2006) e Ferraz Filho et al. (2002). Os animais cruzados REDTAB, STATAB E STAREDTAB apresentaram médias mais elevadas que os animais $\mathrm{TAB}$; resultados semelhantes aos encontrados por Teixeira e Albuquerque (2005).

O PA do STATAB foi mais baixo que o do REDTAB, apesar de apresentarem a mesma idade ao abate (IA) $(\mathrm{P}<0,05)$. O GMD foi mais alto no REDTAB do que nos demais grupos ( $\mathrm{P}<0,05)$. Muniz e Queiroz (1998, 1999) obtiveram desempenhos inferiores aos resultados deste trabalho para animais Nelore e cruzados criados em pastagens de braquiária recebendo 
somente suplemento mineral. Os resultados para P550 (peso aos 550 dias de idade) e G550 (GMD de 230 a 550 dias de idade) foram de $275 \mathrm{~kg}$ e $0,316 \mathrm{~kg}, 318,1 \mathrm{~kg}$ e $0,395 \mathrm{~kg}, 0,355 \mathrm{~kg}$ e $297,3 \mathrm{~kg}$ e $0,355 \mathrm{~kg}$, para Nelore, Angus x Nelore, Brangus $\mathrm{x}$ Nelore, respectivamente. Ferraz Filho et al. $(2002)$ também obtiveram valores inferiores, de $286,45 \mathrm{~kg} \pm 55,41$ para P550, para animais Tabapuã alimentados a pasto.

Os cruzados pesaram, em média, $27,31 \mathrm{~kg}$ à desmama (PD205) e foram abatidos 83 dias em média mais cedo que os $\mathrm{TAB}$, representando $10 \%$ de superioridade em relação à IA. A maior velocidade de crescimento e o abate mais precoce, com a maior participação do cruzamento no rebanho, podem ser observados pelos valores encontrados neste estudo, apresentando idade média de abate de 27 e 23 meses, respectivamente, para o TAB e o REDTAB, ou seja, as raças que apresentaram menor e maior desempenho dentre as outras. Esses valores são inferiores aos relatados por Euclides et al. (1998), com idade ao abate de 31 meses, de novilhos Nelore, em pastagens de Brachiaria decumbens, recebendo ração concentrada (ingestão de $0,8 \%$ do peso vivo) durante a segunda época de seca (da vida desses animais). É importante ressaltar que, no sistema do presente trabalho, a quantidade de suplementação foi menor (ingestão de $0,2 \mathrm{~kg}$ de suplemento para cada $100 \mathrm{~kg}$ de peso vivo) do que o observado no estudo supracitado.

Verificou-se que o grupo contemporâneo (GC), o grupo genético (GG) e a interação entre GC e GG influenciaram significativamente todas as características avaliadas $(\mathrm{P}<0,05)$ (Tab. 2). O PA e GMD foram menores para o GC2 em relação ao $\mathrm{GC} 1$, com valores de $440,0 \mathrm{~kg}$ e $0,579 \mathrm{~kg}$; $484,6 \mathrm{~kg}$ e $0,595 \mathrm{~kg}$, respectivamente. Esse fato pode ser explicado pela menor quantidade de chuva anual média de 2001 a 2003, $1.259 \mathrm{~mm}$, comparado ao período de 2000 a 2002, 1468mm, sendo que essa menor pluviosidade pode ter ocasionado menor oferta de pastagem e menor desempenho animal.

A covariável peso à desmama (PD205) foi significativa nas médias de todas as variáveis dos diferentes GC.

Ao avaliar as médias de desempenho, o REDTAB foi superior no PD205 e no GMD, além de ter permanecido por menos tempo na fazenda que o TAB no $1 \mathrm{GC}$; já no $2 \mathrm{GC}$ eles foram semelhantes na IA, GMD e PA, demonstrando a influência do meio ambiente nas características de desempenho. A superioridade dos cruzados sobre os puros Tabapuã variou de 11 a $16 \%$ para PD205, e, para a média de GMD, o REDTAB foi $18 \%$ superior ao TAB $(\mathrm{P}<0,05)$. Provavelmente essa superioridade está relacionada ao efeito da heterose dos cruzados REDTAB, corroborando os resultados encontrados por Restle et al. (2000), heterose de 9,28\% para GMD, ao comparar o ganho de peso de bovinos em fase de crescimento das raças puras Nelore (N) e Charolês (C) e os cruzamentos $\mathrm{NC}$ e $\mathrm{CN}$. O REDTAB também apresentou superioridade no GMD em relação aos demais GG, demonstrando melhor adaptação ao ambiente (clima e manejo) em relação aos outros cruzamentos. Resultados semelhantes foram obtidos por Gregory et al. (1985) ao avaliarem o desempenho de bovinos $1 / 2$ taurino $\mathrm{x}$ $1 / 2$ zebuíno e $3 / 4$ taurino $x \quad 1 / 4$ zebuíno. Esse resultado pode ser associado à expressão máxima de heterose na primeira geração (F1) em cruzamentos de animais Bos taurus $\mathrm{x}$ Bos indicus.

Ao comparar o desempenho dos animais do $1 \mathrm{GC}$, verifica-se que os grupos genéticos REDTAB e STAREDTAB não apresentaram diferenças significativas $(\mathrm{P}>0,05)$ para $\mathrm{PA}$. Porém, o STAREDTAB permaneceu na fazenda 47 dias a mais que o REDTAB. As médias do PA dos dois cruzados citados acima foram superiores às médias do TAB e do STATAB $(\mathrm{P}<0,05)$. Apesar da semelhança no PA do STATAB e do TAB, o STATAB obteve maior GMD e permaneceu menos tempo na fazenda $(\mathrm{P}<0,05)$. Os animais Tabapuã foram os mais tardios entre os GG, sendo abatidos com 900 dias e com GMD inferior $(\mathrm{P}<0,05)$. Para característica de GMD do 1GC, o REDTAB apresentou superioridade entre os GG, com média de $0,552 \mathrm{~kg} \quad(\mathrm{P}<0,05)$. Esse resultado pode ser associado à expressão máxima da heterose com Bos taurus $\mathrm{x}$ Bos indicus no cruzamento da primeira geração (F1). Superioridade no GMD dos cruzados F1 também foi relatada por Restle et al. (2000) e Muniz e Queiroz (1998, 1999). Os demais cruzados, STATAB e STAREDTAB, apresentaram médias intermediárias para o GMD de 0,491 e $0,479 \mathrm{~kg}$, e o TAB apresentou a menor média, com ganho de $0,405 \mathrm{~kg}$ por dia. 
Tabela 2. Médias observadas do peso à desmama ajustado aos 205 dias (PD205), peso ao abate (PA), ganho médio diário da desmama ao abate (GMD) e idade ao abate (IA), conforme o grupo genético do animal e os grupos contemporâneos (GC) 1 e 2

\begin{tabular}{|c|c|c|c|c|c|}
\hline $\begin{array}{l}\text { Grupo } \\
\text { Genético }\end{array}$ & GC & PD205 (kg) & PA (kg) & GMD (kg) & IA (dias) \\
\hline \multirow[t]{2}{*}{$\mathrm{TAB}$} & 1 & 191,85 & $468,11 b$ & $0,405 \mathrm{c}$ & $900 \mathrm{c}$ \\
\hline & 2 & 194,95 & $453,18 \mathrm{a}$ & $0,490 \mathrm{a}$ & $740 \mathrm{ab}$ \\
\hline Média & & 193,65 & $459,41 \mathrm{~A}$ & $0,454 \mathrm{~B}$ & $807 \mathrm{~B}$ \\
\hline \multirow{2}{*}{ REDTAB } & 1 & 216,89 & $495,74 \mathrm{a}$ & $0,552 \mathrm{a}$ & $710 \mathrm{ab}$ \\
\hline & 2 & 216,18 & $448,10 \mathrm{ab}$ & $0,522 \mathrm{a}$ & $648 \mathrm{a}$ \\
\hline Média & & 216,53 & $472,03 \mathrm{~A}$ & $0,537 \mathrm{~A}$ & $679 \mathrm{~A}$ \\
\hline \multirow[t]{2}{*}{ STATAB } & 1 & 214,30 & $443,82 \mathrm{~b}$ & $0,491 \mathrm{~b}$ & $671 \mathrm{a}$ \\
\hline & 2 & 218,94 & $414,57 \mathrm{~b}$ & $0,394 \mathrm{~b}$ & $723 \mathrm{ab}$ \\
\hline Média & & 215,91 & $433,69 \mathrm{~B}$ & $0,457 \mathrm{~B}$ & $689 \mathrm{~A}$ \\
\hline \multirow[t]{2}{*}{ STAREDTAB } & 1 & 231,17 & $493,24 \mathrm{a}$ & $0,479 \mathrm{~b}$ & $757 \mathrm{~b}$ \\
\hline & 2 & 219,80 & $427,15 \mathrm{ab}$ & $0,386 \mathrm{~b}$ & $754 \mathrm{~b}$ \\
\hline Média & & 224,33 & $453,50 \mathrm{AB}$ & $0,423 \mathrm{~B}$ & $756 \mathrm{~B}$ \\
\hline Média Geral & & 212,80 & 459,64 & 0,464 & 749 \\
\hline
\end{tabular}

TAB: Tabapuã; REDTAB: 1/2Red Angus x 1/2Tabapuã; STATAB: 1/2Santa Gertrudis x 1/2Tabapuã; STAREDTAB: $1 / 2$ Santa Gertrudis x 1/4Red Angus x 1/4Tabapuã, sendo que a raça paterna aparece em primeiro lugar. 1GC: animais nascidos nos meses de setembro de 1999 a fevereiro de 2000; 2GC: nascidos de setembro de 2000 a fevereiro de 2001. Letras maiúsculas diferentes na mesma coluna indicam diferenças entre grupos genéticos $(\mathrm{P}<0,05)$ e letras minúsculas diferentes na mesma coluna indicam diferenças dentro de grupos genéticos $(\mathrm{P}<0,05)$ para comparação dentro de grupo contemporâneo.

As características de desempenho de IA, PA e GMD foram semelhantes para o REDTAB e TAB no $2 \mathrm{GC}$, possivelmente pela interação entre o genótipo e o ambiente, pois o GMD do REDTAB no $2 \mathrm{GC}$ foi inferior ao $1 \mathrm{GC}$, ou seja, pode ter limitado a expressão do genótipo devido ao efeito do ambiente, com menor quantidade de chuva anual média de 2001 a 2003, $1.259 \mathrm{~mm}$, comparado ao período de 2000 a 2002, 1468mm, $\mathrm{e}$, consequentemente, menor oferta de pastagens.

No 2GC os animais REDTAB obtiveram média inferior para IA em relação aos animais STAREDTAB, 648 e 754 dias, respectivamente $(\mathrm{P}<0,05)$. Para TAB, STATAB e STAREDTAB, os resultados de IA foram semelhantes $(\mathrm{P}>0,05)$. Os cruzados STATAB e STAREDTAB não apresentaram diferenças significativas para as médias de GMD ( $\mathrm{P}>0,05)$; entretanto, apresentaram médias inferiores às do REDTAB e $\mathrm{TAB}$, evidenciando inferioridade para essa característica no 2GC. Resultados semelhantes na segunda geração (F2) do cruzamento foram encontrados por Gregory et al. (1985) que, estudando diferentes grupos genéticos de zebuínos e taurinos, verificaram que os bezerros filhos das vacas $1 / 2$ taurino $+1 / 2$ zebuíno, portanto $3 / 4$ taurino $+1 / 4$ zebuíno, desenvolveram-se melhor até a desmama do que bezerros 1/2 zebuíno $+1 / 2$ taurino. Entretanto, no período após a desmama, os bezerros $1 / 2$ taurino $+1 / 2$ zebuíno obtiveram melhor desempenho, em razão da melhor adaptação ao ambiente climático e nutritivo ao qual estavam submetidos.

\section{CONCLUSÕES}

O cruzamento Bos taurus x Bos indicus e o ambiente influenciaram o desempenho produtivo de bovinos criados em sistema semi-intensivo em pastagens de braquiária. Em condição de ambiente mais favorável, o REDTAB pode ser mais precoce, possivelmente pelo maior grau de heterose, obtendo maior ganho de peso diário e peso ao abate com menor idade ao abate, sendo superior ao Tabapuã e aos cruzados de segunda geração (F2). Os cruzados F2 não demonstraram vantagem produtiva em relação ao cruzado de primeira geração $(\mathrm{F} 1)$ e à raça pura. 


\section{REFERÊNCIAS}

BARROS, J.B.G.; BALIEIRO, J.C.C.; ELER, J.P. Estimativas de adaptabilidade e estabilidade fenotípicas em características produtivas em bovinos de corte mestiços criados em diferentes ambientes. Arq. Bras. Med. Vet. Zootec., v.58, p.590-598, 2006.

CRUZ, G.M.; TULLIO, R.R.; ESTEVE, S.N. et al. Peso de abate de machos não-castrados para produção do bovino jovem. 2. Peso, idade e características da carcaça. Rev. Bras. Zootec., v.33, p.646-657, 2004.

EUCLIDES, V.P.B.; EUCLIDES FILHO, K.; ARRUDA, Z.J. et al. Desempenho de novilhos em pastagens de Brachiaria decumbens submetidos a diferentes regimes alimentares. Rev. Bras. Zootec. v.27, p.246-254, 1998

EUCLIDES FILHO, K; FIGUEIREDO, G.R.; EUCLIDES, V.P.B. et al. Eficiência bionutricional de animais da raça Nelore, F1s Valdostana-Nelore e de mestiços de raças europeias adaptadas. Arq. Bras. Med. Vet. Zootec., v.56, p.671-675, 2004.

FERRAZ FILHO, P.B.; RAMOS, A.A.; SILVA, L.O.C. et al. Tendência genética dos efeitos direto e materno sobre os pesos à desmama e pós-desmama de bovinos da raça Tabapuã. Rev. Bras. Zootec., v.31, p.635-640, 2002.

FRIES, L.A. Cruzamentos em gado de corte. In: SIMPÓSIO SOBRE PECUÁRIA DE CORTE, 4., 1996, Piracicaba. Anais... Piracicaba: FEALQ, 1996. p.109-128.

GREGORY, K.E; TRAIL, J.C.M.; MARFLES, H.J.S et al. Characterization of breeds of Bos indicus and Bos taurus cattle for maternal and individual traits. $J$. Anim. Sci., v.60, p.1165-1174, 1985.

KOCH, R.M.; CUNDIFF, L.V.; GREGORY, K.E. Beef cattle creed resource utilization. Braz. J. Genetics, v.12, p.55-80, 1989.

MENEZES, L.F.G.; RESTLE, J.; VAZ, F.N. et al.; Composição física da carcaça e qualidade da carne de novilhos de gerações avançadas do cruzamento alternado entre as raças Charolês e Nelore, terminados em confinamento. Rev. Bras. Zootec., v.34, p.946-956, 2005

MUNIZ, C.A.S.D.; QUEIROZ, S.A. Avaliação do Peso à desmama e do ganho médio de peso de bezerro cruzado, no Estado do Mato Grosso do Sul. Rev. Bras. Zootec., v.27, p.504-512, 1998.
MUNIZ, C.A.S.D.; QUEIROZ, S.A. Avaliação de características de crescimento pós- desmama de animais Nelore puros e cruzados no Estado do Mato Grosso do Sul. Rev. Bras. Zootec., v.28, p.713-720, 1999.

NOGUEIRA, E.; MORAIS, M.G.; ANDRADE, V.J. Efeito do creep feeding sobre o desempenho de bezerros e a eficiência reprodutiva de primíparas Nelore, em pastejo. Arq. Bras. Med. Vet. Zootec., v.58, p.607-613, 2006.

RENNÓ, F.P.; PEREIRA, J.C.; ARAÚJO, C.V. Raças e cruzamentos de bovinos para produção de leite e carne. In: SIMPÓSIO DE BRASILÂNDIA, 2., 2000, Brasilândia. Anais ... Brasilândia: UFV: 2000, p.75100.

RESTLE, J.; ALVES FILHO, D.C.; FATURI, C. et al. Desempenho na fase de crescimento de machos bovinos inteiros ou castrados de diferentes grupos genéticos. Rev. Bras. Zootec., v.29, p.1036-1043, 2000

RIBEIRO, S.H.A.; PEREIRA, J.C.C; VERNEQUE, R.S. et al. Efeito da covariância genética aditivomaterna sobre estimativas de parâmetros genéticos e em avaliações genéticas de características de crescimento de animais Tabapuã. Arq. Bras. Med. Vet. Zootec., v.61, p.401-406, 2009.

ROSA, A.N. Variabilidade fenotípica e genética do peso adulto e da produtividade acumulada de matrizes em rebanhos de seleção da raça Nelore no Brasil. 1999. 120f. Tese (Doutorado em Ciências) Faculdade de Medicina de Ribeirão Preto, Universidade de São Paulo, Ribeirão Preto.

SAKAGUTI, E.S.; SILVA, M.A.; QUAAS, R.L. et al. Avaliação do crescimento de bovinos jovens da raça Tabapuã, por meio de análises de funções de covariâncias. Rev. Bras. Zootec., v.32, p.864-874, 2003

TEIXEIRA, R.A.; ALBUQUERQUE, M.L.G. Heteroses materna e individual para ganho de peso pré-desmama em bovinos Nelore $\times$ Hereford e Nelore $\times$ Angus. Arq. Bras. Med. Vet. Zootec., v.57, p.518523,2005 .

STATISTICAL Analysis Sistem. USER'S guide: statistics. Version 6.4 ed. Cary, NC: SAS Institute, 1990.

VIEIRA, A.; LOBATO, J.F.P.; CORREA, E.S. et al. Produtividade e eficiência de vacas Nelore em pastagem de Brachiaria decumbens Stapf nos cerrados do Brasil Central. Rev. Bras. Zootec., v.34, p.13571365, 2005. 